\title{
Effect of Acrylamide on the Tongue Musculature of Adult Male Albino Rat and the Possible Protective Role of Vitamin E: Light and Electron Microscopic Study
}

\author{
NABILA Y. ABD EL-HALIM, M.D.*; MOHAMED M. SOFII, M.D.**; EMAN A.M. MOHAMED, M.Sc.** and \\ MOGEDA M. NASRALLA, M.D.*
}

The Department of Anatomy \& Embryology, Faculty of Medicine, Cairo* and Fayoum** Universities, Egypt

\begin{abstract}
Background: Acrylamide is a potent toxin and carcinogen, its hazards result from its increased accumulation in the process of cooking food materials.

Aim of Study: This study aimed to demonstrate the effects of acrylamide on the skeletal muscle fibers of adult male albino rat tongue for two different durations, using light and electron microscopic study and to investigate the possible protective effect of Vitamin E co-administration.

Material and Methods: Sixty adult male albino rats were divided into six groups, each group included ten rats. Group I (control). Group II (Sham control). Group III received acrylamide for 20 days. Group VI received acrylamide for 40 days. Group V received acrylamide and Vitamin E, with 30 minutes interval between the two doses, for 20 days. Group VI received acrylamide and Vitamin E with 30 minutes interval between the two doses, for 40 days. All medications were given orally by gastric gavage. At the end of the experiment the tongue was dissected out for light and electron microscopic studies.

Results: Light microscopic examination revealed that acrylamide lead to skeletal muscle damage in rat tongue. In the form of, fragmentations, splitting and inflammatory cellular infiltrations. Electron microscopic study of Group III revealed degeneration of mitochondria, these changes became worse with prolonged duration of exposure. This toxic effect of acrylamide could be minimized when Vitamin $\mathrm{E}$ is given concomitantly with it.
\end{abstract}

Conclusion: Acrylamide lead to histological changes in rat tongue. Vitamin $\mathrm{E}$ minimized this changes due to its antioxidant effect.

Key Words: A crylamide - Tongue - Histology-Electron microscope Vitamin E.

\section{Introduction}

ACRYLAMIDE, one of the major environmental public health problems, found in carbohydraterich food prepared at high temperatures which are

Correspondence to: Dr. Mogeda Mahdy Nasralla, E-Mail:mogedam@yahoo.com widely consumed by humans. Consumption of these foods may result in significant human exposure to acrylamide [1]. Acrylamide is a low molecular weight, water soluble vinyl monomer; these properties facilitate its rapid absorption and distribution through body [2] .

Acrylamide has been extensively investigated and has a large database of very complex toxicity. The results of the studies indicate that acrylamide is carcinogenic in rodents and produces toxic effects on the different body organs, e.g. kidney, spleen and liver [3,4].

El-Sayyad et al., [5] reported that sections of the skeletal muscles of tongue of rats treated with acrylamide showed vacuolated spaces and many of spotty necrotic zones. Partial hyaline necrosis was detected in the majorities of the skeletal muscle fibers. Focal necrotic zones with dispersed nuclei were detected. Loosely separated skeletal muscle fibers associated with lacking of their regular arrangement and densely collected inflammatory cells in between were observed.

The administration of acrylamide was associated with a dose related increase in squamous cell papilloma of the tongue and combined squamous cell papilloma and carcinoma of the tongue in rats [6].

Exposure to acrylamide resulted in reduction of lingual keratinization, atrophy of different tongue papillae and degeneration of the apical taste buds of fungiform papillae and abundant leucocytic infilterations appeared in the lamina propria of the tongue of experimental rats [7].

Longitudinal sections of the skeletal muscles of the tongue of acrylamide treated rats showed disruption of $\mathrm{Z}$ line, partial loss of myofilaments, 
marked aggregation of mitochondria and vacuolated mitochondria also appeared [8].

Oxidative stress and apoptosis play an important role in acrylamide-induced damage in skeletal muscle fibers of the tongue. Prasad, [9] reported that acrylamide-induced cytotoxicity was relevant to oxidative stress, the cytotoxic properties of acrylamide lead to generation of Reactive Oxygen Species (ROS) causing cytotoxic and genotoxic effects.

Some strategies have been postulated to reduce acrylamide mediated cytotoxicity by using natural antioxidant like Vitamin E. Vitamin E can protect cellular structures against damage from free radicals such as peroxy radical, hydroxyl radical and superoxide. It has protective effect from oxidation products such as Malondialdehyde (MDA) and hydroxynonenal. Vitamin $\mathrm{E}$ was utilized to prevent the toxic effects of acrylamide on the testes [10]

The aim of this study is to investigate the effect of acrylamide on the skeletal muscle fibers of tongue of adult male albino rat and the possible protective role of Vitamin E co-administration, for a short duration (twenty days) and a long duration (forty days) by using light and electron microscopic study.

\section{Material and Methods}

\section{Material:}

Animals:

The research was done in 2017. This study was performed using 60 adult male albino rats weighing 180-220gm. The rats were obtained from Animal House, Faculty of Medicine, Cairo University. The rats were acclimatized in the laboratory for a period of two weeks before carrying out the experiment. They were housed in cages, five rats/cage under standard laboratory and environmental conditions. They were allowed free access to food and distilled water. All the animals were cared for in accordance with the institutional ethical guidelines and protocol was approved by the Kasr Al-Einy Experimental Ethics committee. The rats were randomly divided into six experimental groups; each group consists of ten rats:

- Group I: (Normal control): Rats received no medications.

- Group II: (Sham control): Rats received normal saline solution and Vitamin E dissolved in corn oil orally once daily by gavage, with 30 minutes interval between the two doses, for 40 days.
- Group III: Rats received acrylamide orally once daily by gavage for 20 days [11].

- Group IV: Rats received acrylamide orally once daily by gavage for 40 days [8]

- Group V: Rats received acrylamide and Vitamin E orally once daily by gavage, with 30 minutes interval between the two doses, for 20 days [11]

- Group VI: Rats received acrylamide and Vitamin E orally once daily by gavage, with 30 minutes interval between the two doses, for 40 days [8].

\section{Chemicals:}

Acrylamide (99.9 purity), obtained from sigma chemical Co. Each 20mg of acrylamide was dissolved in $5 \mathrm{ml}$ saline solution and given orally by gastric gavage in a daily dose of $20 \mathrm{mg} / \mathrm{kg}$ body weight). Each rat was given the calculated doseVitamin E, (Capsules 400mg/capsule) obtained from sigma chemical Co. Each Vitamin E capsule $400 \mathrm{mg}$ was dissolved in $20 \mathrm{ml}$ of corn oil and given orally by gastric gavage in a daily dose of $100 \mathrm{mg} / \mathrm{kg}$ body weight [12]. Each rat was given the calculated dose.

Rats from Groups (I and II) were divided into two subgroups (5 rats in each subgroup), 5 rats were sacrificed after 20 days and 5 rats were sacrificed after 40 days, rats from Groups (III and V) were sacrificed after 20 days, rats from Groups (IV and VI) were sacrificed after 40 days.

1- At the end of the experiment, the rats of each group were anesthetized using an over dose of anesthesia by intraperitoneal injection of phenobarbital sodium (40mg-kg). The rats were sacrificed by cervical dislocation and the tongue was excised and dissected. Each tongue was divided horizontally into two parts: A part was fixed in $10 \%$ formol saline. Paraffin sections of 5 microns thickness were obtained and prepared for light microscopic study. The other part was fixed in $2.5 \%$ glutarldehyde in $0.1 \mathrm{M}$ phosphate buffer solution (PH 7.4) at $4^{\circ} \mathrm{C}$ then fixed in $1 \%$ osmium tetroxide and prepared for electron microscopic study.

\section{Methods:}

\section{Light microscopic study:}

For histological examination, coronal sections of the tongue will be stained with hematoxylin and eosin (H \& E), Masson's trichrome and P.A.S. stains.

\section{2- Histomorphometric study:}

Quantitative study was performed by the aid of Leica Quin 500 software (Leica Imaging System 
Ltd., Cambridge, England) using the software Quination500 England. The measurements were made on ten non-overlapping microscopic fields randomly from each slide and examined within the standard measuring frame at $\mathrm{x} 400 . \mathrm{x}$ the area percent was determined within the measuring frame. The following measurements were taken:

- Percentage of collagen fibers in Masson's trichrome stained sections.

- PAS optical density in PAS stained sections.

\section{Electron microscopic study:}

The ultrastructural study of tongue samples will be carried out with transmission electron microscope.

\section{Statistical analysis:}

Data was expressed as mean value $\pm \mathrm{SD}$. Comparisons between two related groups were carried out by paired $t$-test while comparisons between more than two groups were carried out by ANOVA test (analysis of variance) followed by Tukey's test.

\section{Statistical analysis was done for:}

A- The percentage of collagen fibers in all groups.

B- The mean PAS optical density in all groups.

\section{Results}

Light microscopic results:

Groups I \& II (normal and sham control groups):

The light microscopic results of the normal and sham control groups were similar.

The histological sections of the rat tongue of the normal and sham control groups stained with haematoxylin and eosin showed bundles of skeletal muscle fibers running in different directions, the skeletal muscle fibers running longitudinally arranged in bundles or fascicles of muscle fibers separated by perimysial connective tissue, the muscle fibers appeared parallel, long, cylindrical and non- branching with acidophilic crossly striated sarcoplasm. The nuclei were multiple, elongated and peripheral in position under the sarcolemma. The fibers were connected together by connective tissue endomysium Fig. (1A).

The skeletal muscle fibers running transversely appeared polygonal with acidophilic myofibrils and peripherally located nuclei. The endomysial connective tissue among the muscle fibers showed some blood vessels Fig. (1A).

Sections stained with Masson's trichrome visualized a normal pattern of collagen deposition around skeletal muscle fibers Fig. (1B).

Sections stained with PAS, the skeletal muscle fibers were shown to have a strong positive PAS reaction in the form of small red granules filling their sarcoplasm denoting considerable amounts of glycogen Fig. (1C).

Group III (animals receiving acrylamide for short duration):

In the histological sections of the rat tongue of Group III (after 20 days of acrylamide administration), the skeletal muscle fibers showed abnormal wavy course of the muscle fibers with splitting of the myofibers and fragmentation of the sarcoplasm Figs. (2A-C, 3A). In addition, dilated congested blood vessels with fibrosed walls Fig. (2B) and mononuclear cellular infiltration appeared in the connective tissue perimysium Fig. (4) and darkly stained pyknotic nuclei were also detected Fig. (3A). Using Masson's trichrome stain technique the deposition of collagen fibers increased around the skeletal muscle fibers Fig. (3A). In specimens stained with PAS, the skeletal muscle fibers showed faint PAS reaction indicating reduced glycogen content Fig. (3B).

Group IV (animals receiving acrylamide for long duration):

In the histological sections of the rat tongue of Group IV (after 40 days of acrylamide administration), the splitting and fragmentation of the myofibers were markedly increased. Dense pyknotic nuclei and remnants of nuclei were also detected Fig. (4A). Markedly dilated and congested blood vessels with fibrosed walls were observed Fig. (4A). Using Masson's trichrome stain technique the deposition of collagen fibers was markedly increased around the skeletal muscle fibers Fig. (4B). In specimens stained with PAS, the skeletal muscle fibers showed markedly faint PAS reaction indicating markedly reduced glycogen content Fig. (a).

Group V (animals receiving acrylamide and Vitamin E for short duration):

The histological sections of the rat tongue of Group V (after 20 days of acrylamide and Vitamin E administration), showed mild focal histological changes. Few fibers still have wavy course with mild splitting and fragmentation Fig. (5A). In Masson's trichrome stained sections, there was mild increase in the collagen fibers deposition around the skeletal muscle fibers Fig. (5B). Sections stained with PAS revealed a moderate glycogen content as demonstrated by their moderately positive PAS reaction Fig. (5C). 
Group VI (animals receiving acrylamide and Vitamin E for long duration):

The histological sections of the rat tongue of Group VI (after 40 days of acrylamide and Vitamin E administration), showed moderate focal histological changes. Some fibers still have wavy course with moderate splitting and fragmentation Fig. (6A). Using Masson's trichrome stain technique the deposition of collagen fibers was moderately increased around the skeletal muscle fibers Fig. (6B). In specimens stained with PAS, the skeletal muscle fibers showed moderately faint PAS reaction indicating reduced glycogen content Fig. (6C).

\section{Electron microscopic results:}

Groups I \& II (normal and sham control groups): The electron microscopic results of the normal and sham control groups were similar. Using the electron microscope, the sarcoplasm appeared filled with myofibrils arranged parallel to the long axis of the myofiber. The myofibrils showed regular arrangement of alternating light (I) and dark (A) bands. Z line was seen bisecting the light band. Sarcomeres were seen between two successive $\mathrm{Z}$ lines Fig. ((7A).

Group III (animals receiving acrylamide for short duration): Using the electron microscope, micrographs of skeletal muscle fibers of Group III showed aggregation of mitochondria of different size and shape in the subsarcolemmal and
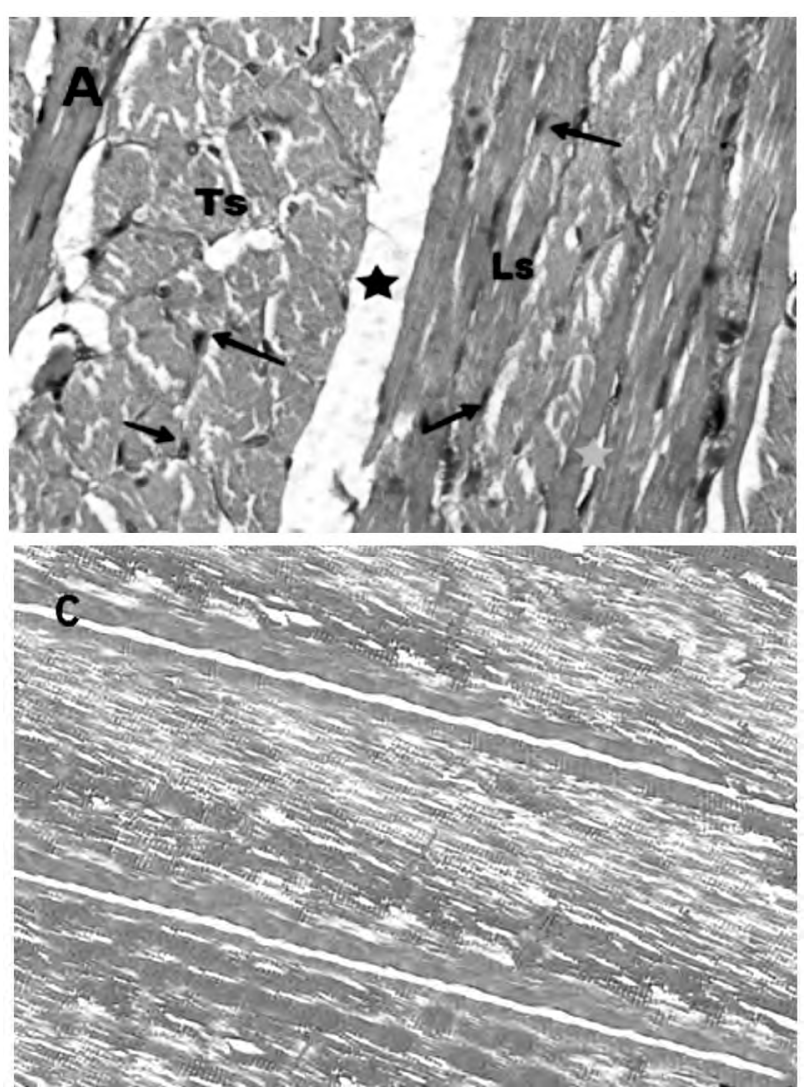

intermyofibrillar spaces. Degeneration of parts of myofibrils and disruption of $Z$ lines were observed. Fusion of some mitochondria to form giant and vacuolated mitochondria appeared Fig. (7B).

Group IV (animals receiving acrylamide for long duration): Using the electron microscope, micrographs of skeletal muscle fibers of Group IV, areas of marked myofibrillar degeneration with loss of sarcomere pattern and disruption of $\mathrm{Z}$ lines were observed. Marked aggregations of giant and vacuolated mitochondria in the subsarcolemmal and interm-yofibrillar spaces were detected Fig. (7C).

Group V (animals receiving acrylamide and Vitamin E for short duration): Using the electron microscope, micrographs of skeletal muscle fibers of Group V showed mild degeneration of myofibrils, nearly normal patterns of sarcomeres with parallel arrangement, light and dark bands and $\mathrm{Z}$ lines were preserved Fig. (8A).

Group VI (animals receiving acrylamide and Vitamin E for long duration): Using the electron microscope, micrographs of skeletal muscle fibers of Group VI showed areas of moderate myofibrillar degeneration and disruption of $\mathrm{Z}$ lines. Moderate aggregations of giant and vacuolated mitochondria in the subsarcolemmal and intermyofibrillar spaces were detected Fig. (8B).

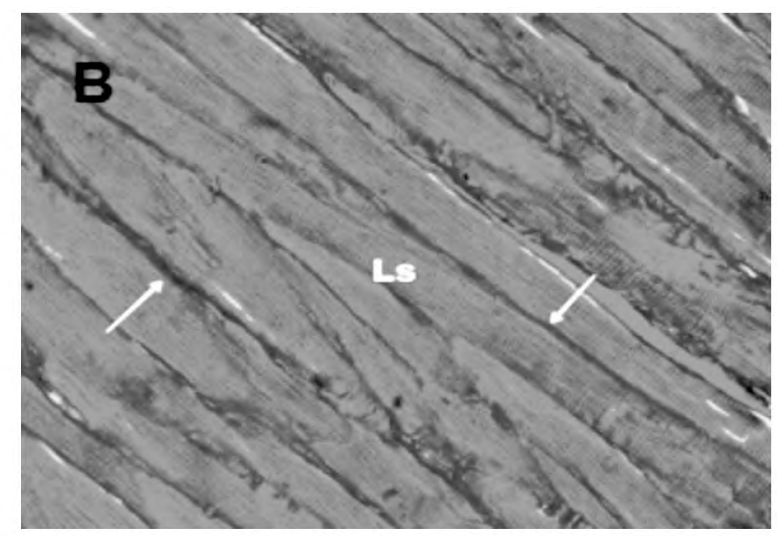

Fig. (1): A-A photomicrograph of a section of tongue of a rat from normal control group showing normal skeletal muscle fibers running longitudinally (Ls) and transversely (Ts) with peripherally located nuclei (black arrow). Bundles of skeletal muscle fibers are separated by connective tissue perimysium (black star) and individual fibers are separated by loose connective tissue endomysium (green star). (Hx \& $\mathrm{E} ; \mathrm{X} 400)$. B- A photomicrograph of a section of tongue of a rat from normal control group showing the normal pattern of collagen fibers deposition (white arrow) between the skeletal muscle fibers running longitudinally (Ls). (Masson's trichrome; $\mathrm{X} 400$ ). C- A photomicrograph of a section of tongue of a rat from normal control group exhibiting a strong positive PAS reaction of the skeletal muscle fibers in the form of small red granules in the sarcoplasm (green arrow). (PAS; X400). 

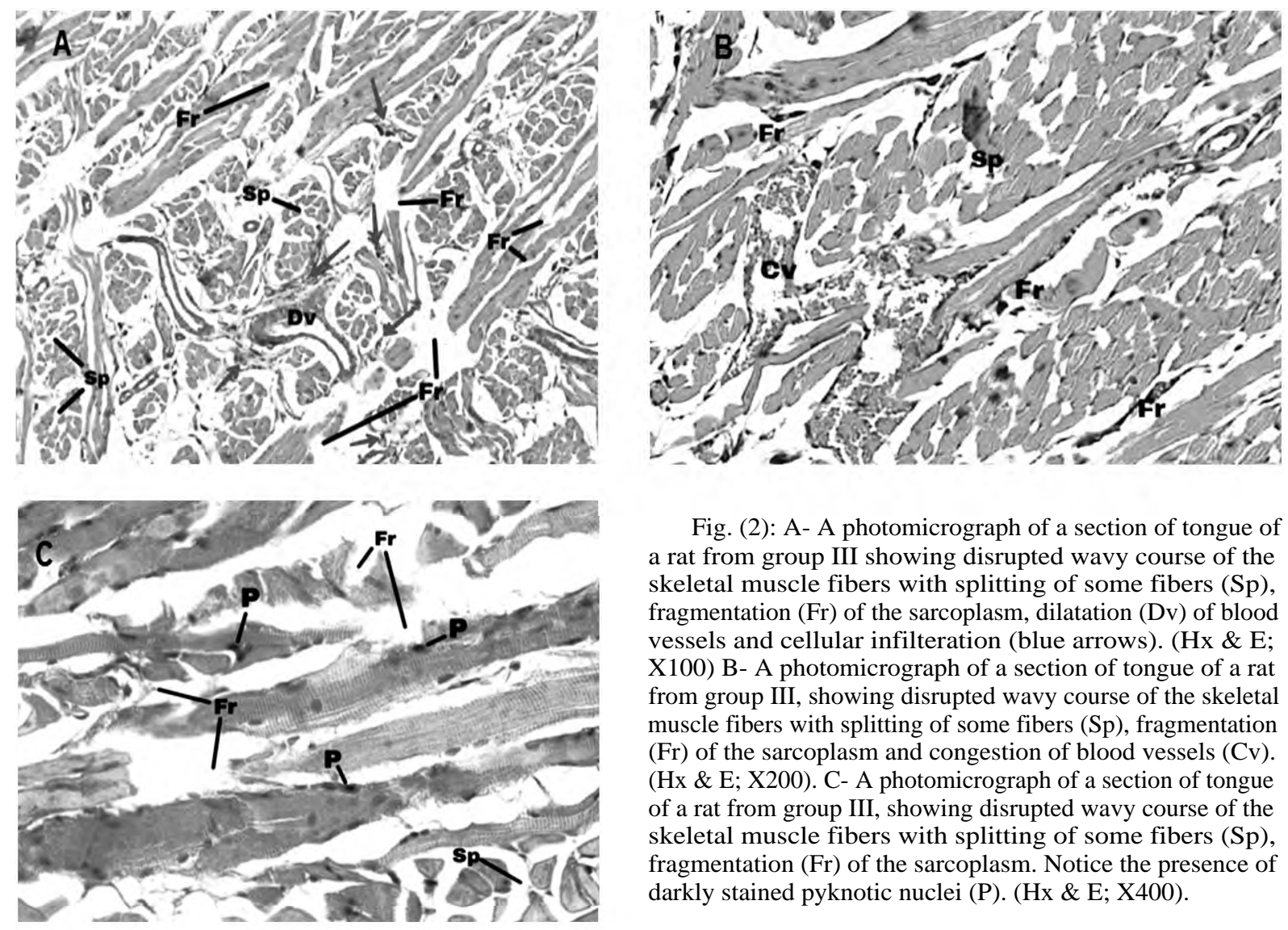

Fig. (2): A- A photomicrograph of a section of tongue of a rat from group III showing disrupted wavy course of the skeletal muscle fibers with splitting of some fibers (Sp), fragmentation (Fr) of the sarcoplasm, dilatation (Dv) of blood vessels and cellular infilteration (blue arrows). (Hx \& E; X100) B- A photomicrograph of a section of tongue of a rat from group III, showing disrupted wavy course of the skeletal muscle fibers with splitting of some fibers (Sp), fragmentation (Fr) of the sarcoplasm and congestion of blood vessels $(\mathrm{Cv})$. (Hx \& E; X200). C- A photomicrograph of a section of tongue of a rat from group III, showing disrupted wavy course of the skeletal muscle fibers with splitting of some fibers ( $\mathrm{Sp}$ ), fragmentation (Fr) of the sarcoplasm. Notice the presence of darkly stained pyknotic nuclei (P). (Hx \& E; X400).
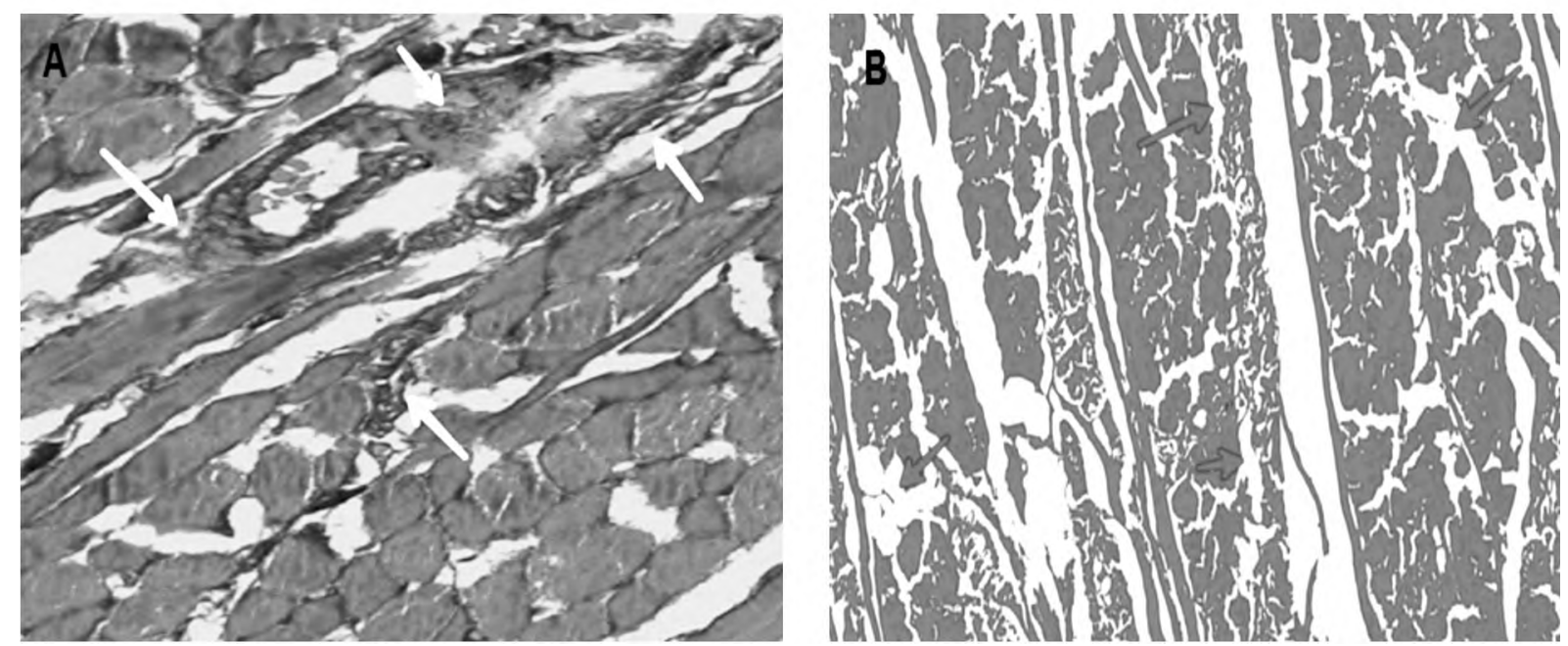

Fig. (3): A- A photomicrograph of a section of tongue of a rat from Group III, showing increased collagen fibers deposition (white arrow) between the skeletal muscle fibers running in different directions and around blood vessels. (Masson's trichrome; X400). B- A photomicrograph of a section of tongue of a rat from Group III exhibiting a faint PAS reaction of the skeletal muscle fibers (green arrow). (PAS; X400). 

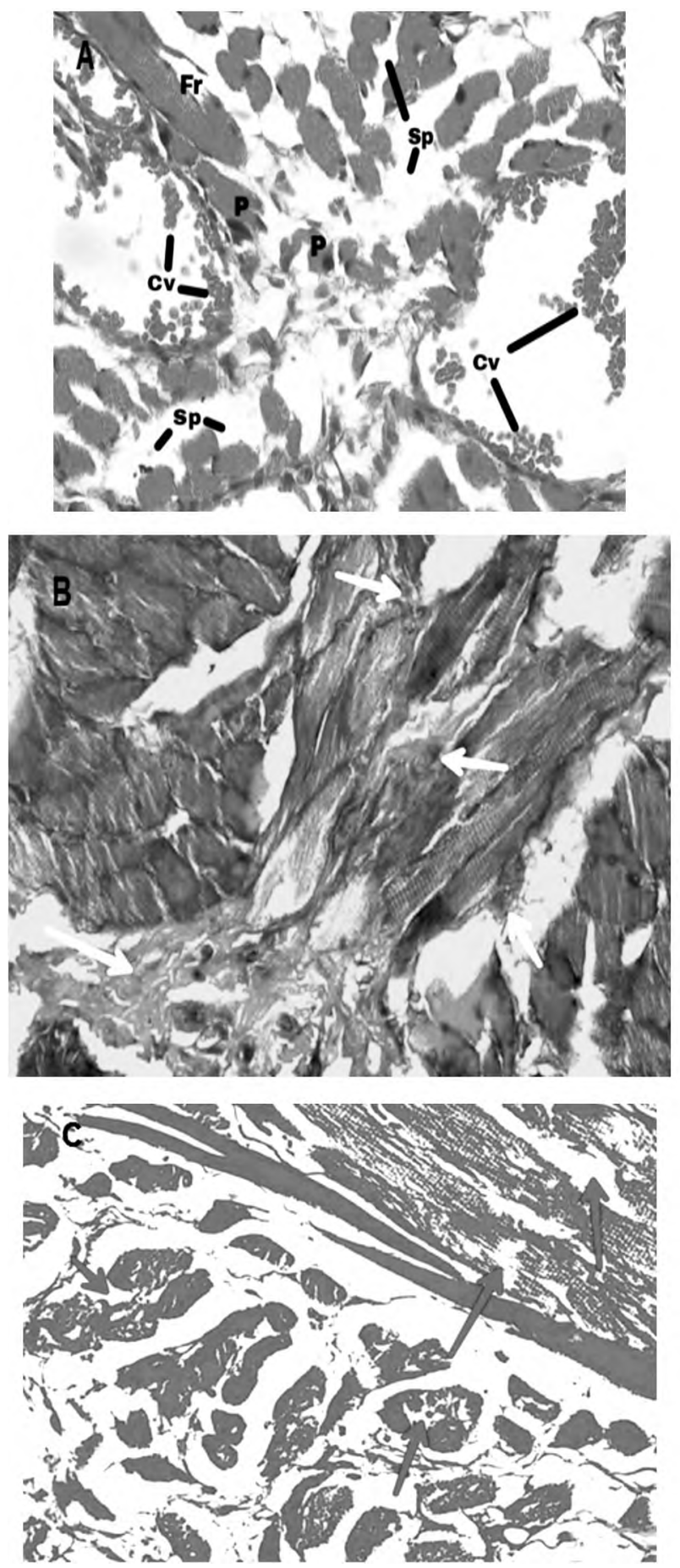

Fig. (4): A- A photomicrograph of a section in the tongue of a rat from Group IV, showing marked disrupted wavy course of the skeletal muscle fibers with splitting of some fibers ( $\mathrm{Sp}$ ), marked fragmentation (Fr) of the sarcoplasm, markedly dilated and congested blood vessels $(\mathrm{Cv})$. Notice the presence of darkly stained pyknotic nuclei (P). (Hx \& E; $\mathrm{X} 400$ ). B- A photomicrograph of a section of tongue of a rat from Group IV, showing marked increase in collagen fibers deposition (white arrow) around the skeletal muscle fibers running in different directions. (Masson's trichrome; X400). $\mathrm{C}$ - A photomicrograph of a section in the tongue of a rat from Group IV exhibiting a markedly faint PAS reaction of the skeletal muscle fibers (green arrow). (PAS; X400).
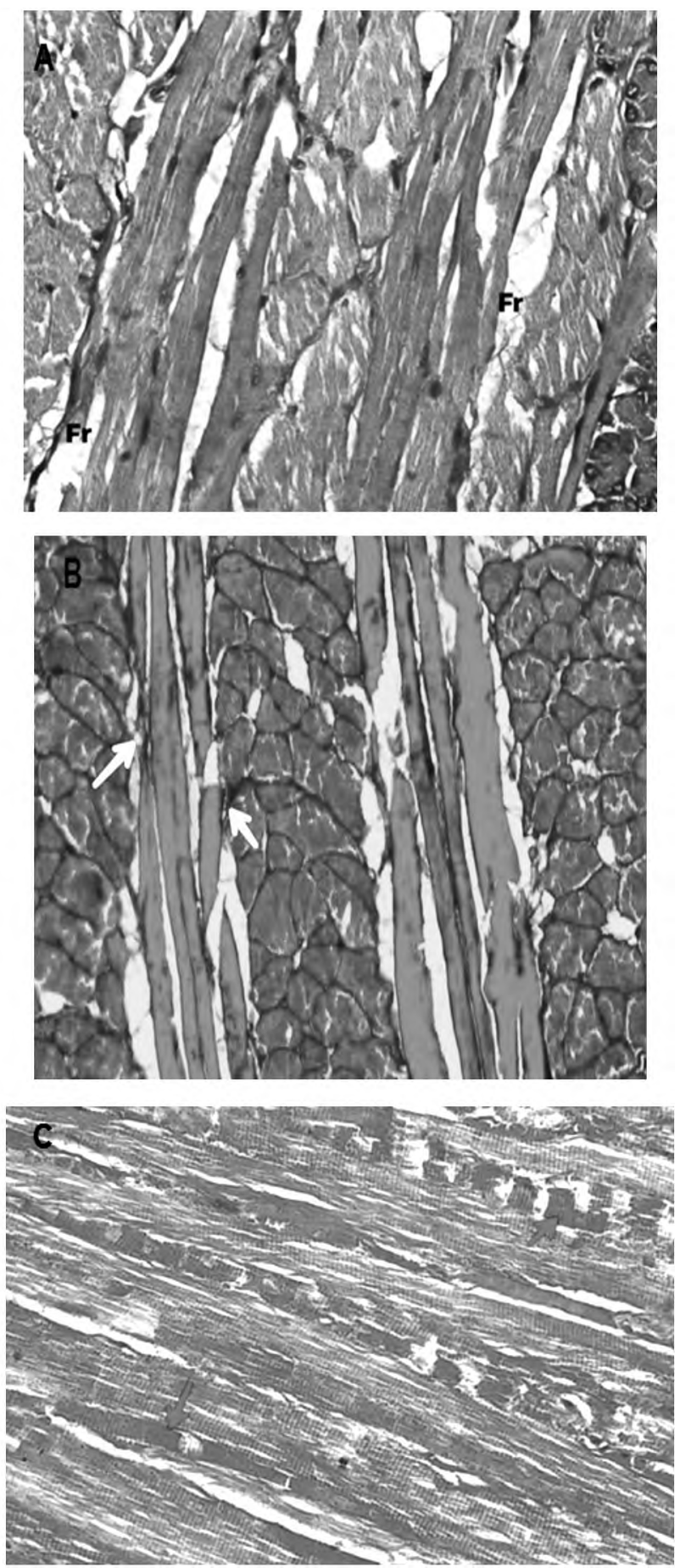

Fig. (5): A- A photomicrograph of a section of tongue of a rat from Group V, showing nearly normal skeletal muscle fibers running longitudinally. Minute fragmentations (Fr) occasionally found. (Hx \& E; X400). B- A photomicrograph of a section of tongue of a rat from the Group V, showing nearly normal pattern of collagen fibers deposition (white arrow) around the skeletal muscle fibers running in different directions. (Masson's trichrome; X400). C- A photomicrograph of a section of tongue of a rat from the group $\mathrm{V}$ exhibiting a moderately positive PAS reaction of the skeletal muscle fibers. (PAS; X400). 

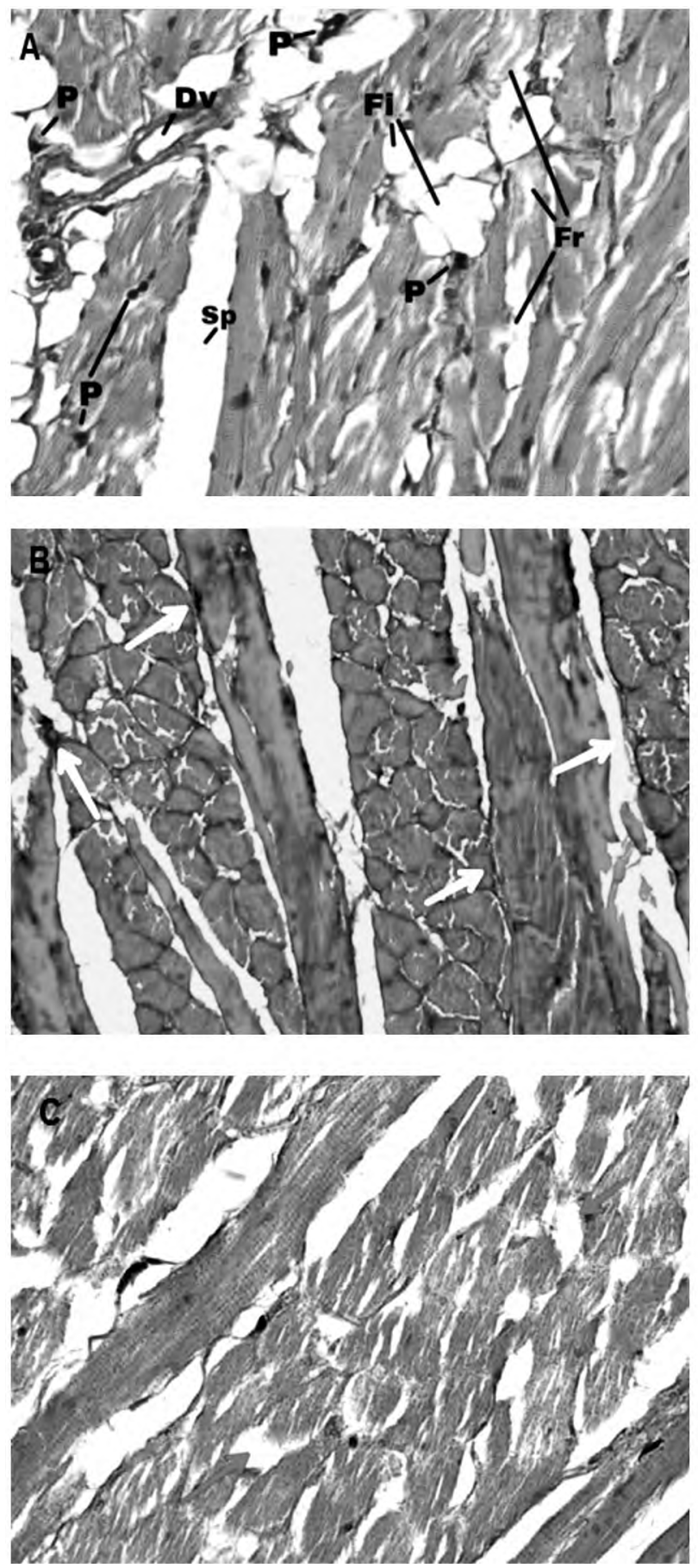

Fig. (6): A- A photomicrograph of a section of tongue of a rat from group VI, showing moderate skeletal muscle fibers splitting (Sp) and moderate fragmentations (Fr). Fatty infilteration (Fi), dilatation (Dv) and darkly stained pyknotic nuclei (P) also appeared. (Hx \& E; X400). B- A photomicrograph of a section of tongue of a rat from the Group VI, showing nearly normal pattern of collagen fibers deposition (white arrow) between the skeletal muscle fibers running in different directions. (Masson's trichrome; X400). C- A photomicrograph of a section of tongue of a rat from the Group VI exhibiting a moderately faint PAS reaction of the skeletal muscle fibers. (PAS; X400).
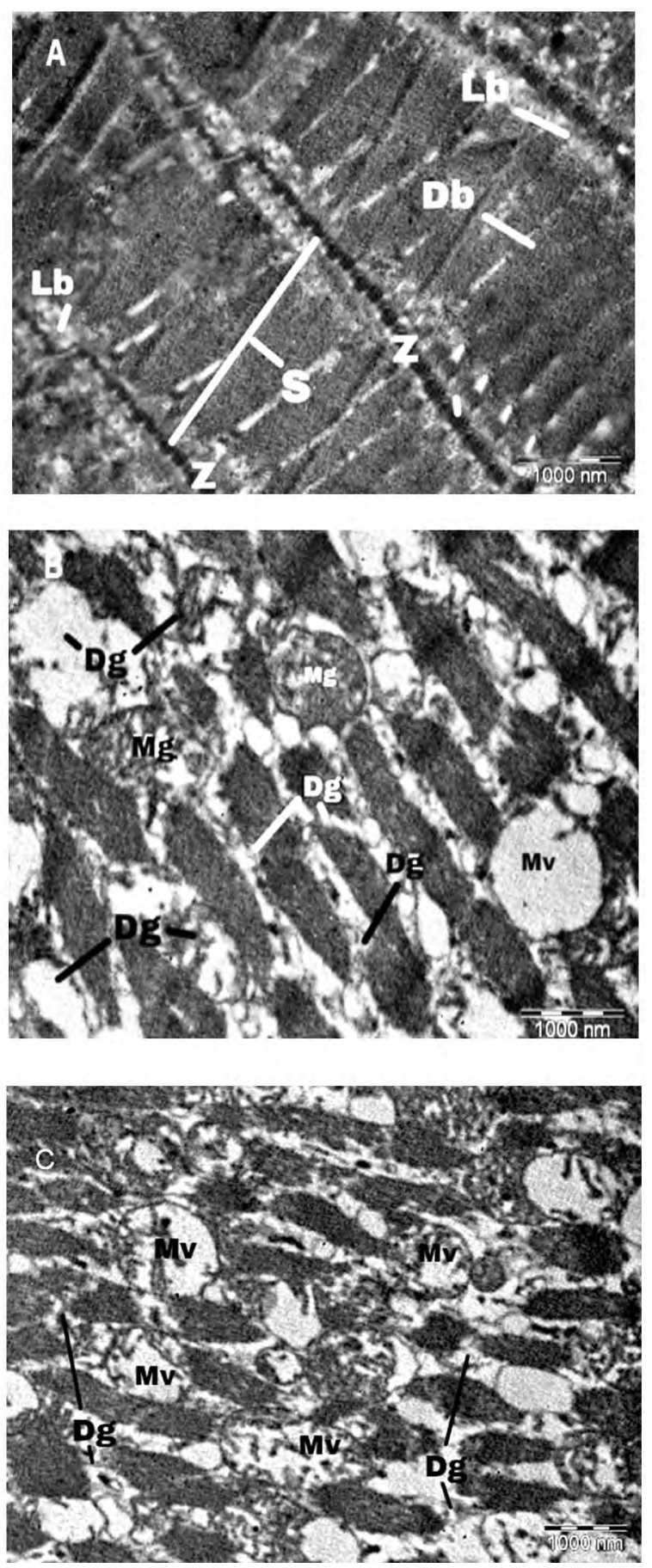

Fig. (7): A- An electron photomicrograph of a section of tongue of a rat from normal control group showing parallel arrangement of myofibrils with light bands $(\mathrm{Lb})$ and dark bands (Db). Sarcomeres (S) are seen between two successive $\mathrm{Z}$ lines (Z). (X10000). B- An electron photomicrograph of a section of tongue of a rat in Group III, showing aggregation of giant mitochondria $(\mathrm{Mg})$ and vacuolated mitochondria $(\mathrm{Mv})$, degeneration of myofibrils $(\mathrm{Dg})$, notice the disruption of Z lines and the loss of sarcomere pattern. (X10000). C- An electron photomicrograph of a section of tongue of a rat in Group IV, showing marked degeneration of myofibrils (Dg), marked aggregations of vacuolated mitochondria $(\mathrm{Mv})$. Notice the loss of sarcomere pattern. (X10000). 

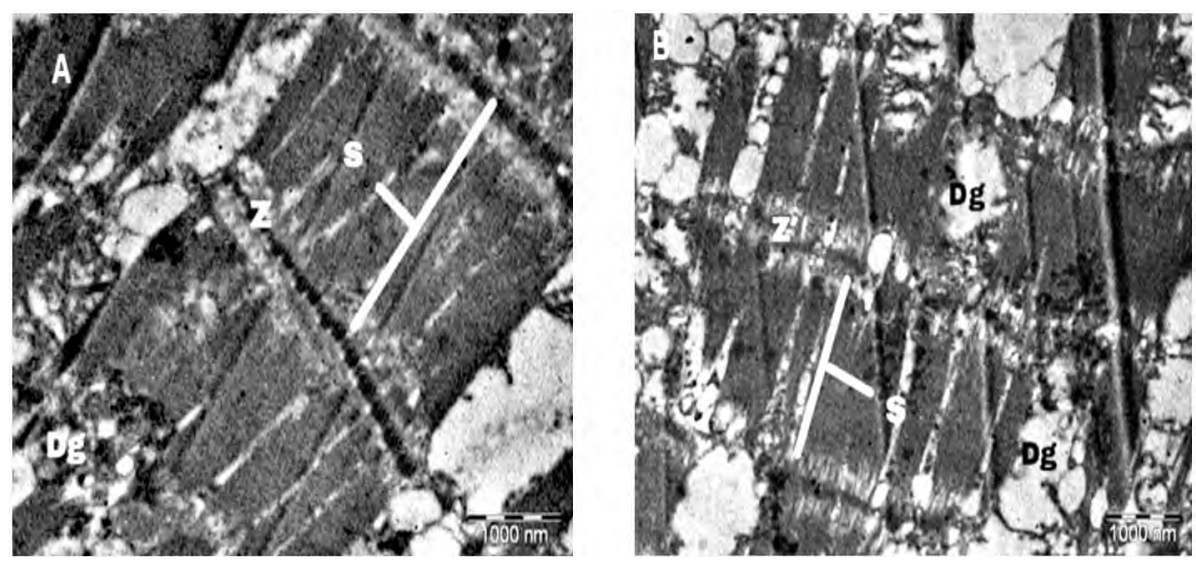

Fig. (8): A- An electron photomicrograph of a section of tongue of a rat from Group V, showing mild degeneration of myofibrils (Dg), nearly normal pattern of sarcomeres (S) and Z lines (Z) is preserved. (X10000). B- An electron photomicrograph of a section of tongue of a rat from Group VI, showing moderate degeneration of myofibrils (Dg), nearly normal pattern of sarcomeres $(\mathrm{S})$ and $\mathrm{Z}$ lines $(\mathrm{Z})$ is preserved. (X10000).

\section{Histomorphometric and statistical results:}

\section{A- Statistical analysis of the mean area percent of collagen fibers (Table 1) and Histogram (1):}

Statistical analysis of data showed that there was no statistical significant difference in the mean percent area of collagen fibers between the normal Group I and sham control Group II. The mean area percent of collagen fibers in Group III was highly significant different compared to the control group and in Group IV the difference was highly significant increased when compared to the control group. In Group V, the mean area percent of collagen fibers was non significant compared to control group but was highly significant different compared with Group III and Group IV. In Group VI the difference was non significant compared to control group but was highly significant different compared with Group IV. The F-ratio high numerical value (11.986) indicates a high overall significance among the different animal groups.

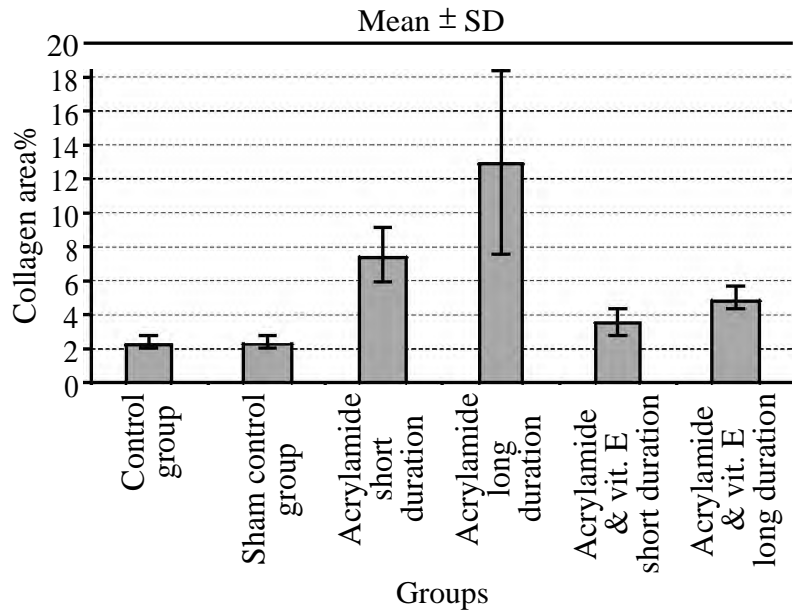

Histogram (1): Bar chart of the mean area\% of collagen fibers in all groups.

\section{$B$ - Statistical analysis of the mean PAS optical density (Table 2) and Histogram (2):}

Statistical evaluation of the mean values of the PAS optical density in the different experimental groups showed no statistically significant difference between the normal control Group I and sham control Group II. On the other hand, the mean glycogen content in Group III showed highly significant different compared to the control group and in Group IV the difference was highly significant decreased when compared to the control group. In Group V, the mean glycogen content was non significant compared to control group but was significant different compared with Group III and was highly significant different compared with Group IV. In Group VI the difference was non significant compared to control group and was significant different compared with Group IV. The F-ratio high numerical value (12.426) indicates a high overall significance among the different animal groups.

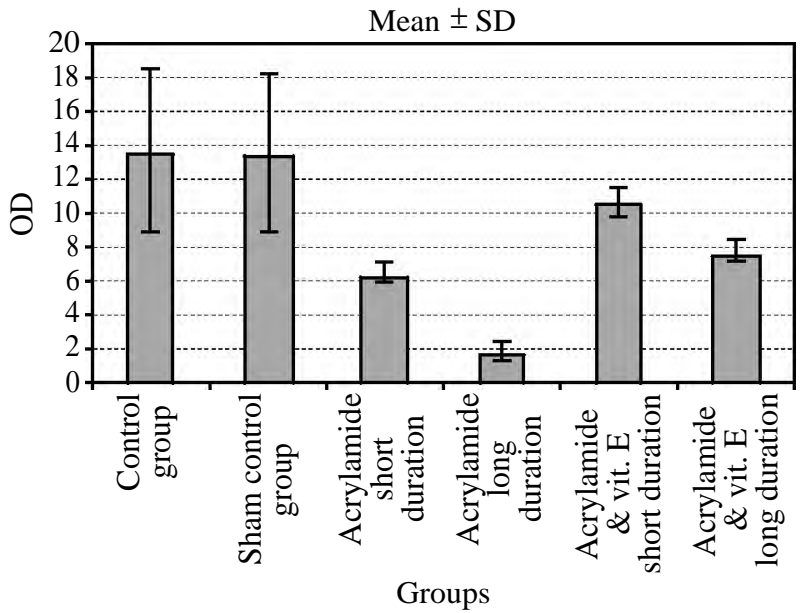

Histogram (2): Bar chart of the mean PAS optical density (OD) in all groups. 
Table (1): The mean area percent of collagen fibers in all groups using ANOVA test.

\begin{tabular}{|c|c|c|c|}
\hline Groups & Mean $\pm S D$ & $p$-value & F-ratio \\
\hline $\begin{array}{l}\text { - Group I (Control } \\
\text { group) }\end{array}$ & $2.38 \pm 0.41$ & - & \\
\hline $\begin{array}{l}\text { - Group II (Sham } \\
\text { control group) }\end{array}$ & $2.42 \pm 0.24$ & $\begin{array}{l}0.982 * \\
0.007 * * * \\
<0.0001 * * * * \\
0.475 * * * * * \\
0.146 * * * * * *\end{array}$ & \\
\hline $\begin{array}{l}\text { - Group III } \\
\text { (Acrylamide short } \\
\text { duration) }\end{array}$ & $7.51 \pm 1.60$ & $\begin{array}{l}0.006 * \\
0.007 * * \\
0.004 * * * * \\
0.032 * * * * * \\
0.141 * * * * * *\end{array}$ & \\
\hline $\begin{array}{l}\text { - Group VI } \\
\text { (Acrylamide long } \\
\text { duration) }\end{array}$ & $12.99 \pm 5.42$ & $\begin{array}{l}<0.0001 * \\
<0.0001 * * \\
0.004 * * * \\
<0.0001 * * * * * \\
<0.0001 * * * * * *\end{array}$ & 11.986 \\
\hline $\begin{array}{l}\text { - Group V } \\
\text { (Acrylamide \& Vit. } \\
\text { E short } \\
\text { duration) }\end{array}$ & $3.63 \pm 0.77$ & $\begin{array}{l}0.461 * \\
0.475 * * \\
0.032 * * * \\
<0.0001 * * * * \\
0.440 * * * * * *\end{array}$ & \\
\hline $\begin{array}{l}\text { - Group VI } \\
\text { (Acrylamide \& Vit. } \\
\text { E long } \\
\text { duration) }\end{array}$ & $4.95 \pm 0.69$ & $\begin{array}{l}0.140 * \\
0.146 * * \\
0.141 * * * \\
<0.0001 * * * * \\
0.440 * * * * *\end{array}$ & \\
\hline
\end{tabular}

$p$-value is significant $\leq 0.05$.

* : With group 1.

** : With group 2 .

$* * *$ : With group 3.

\#SD: Standard deviation.

The F-ratio: Overall significance among the different animal groups.

\section{Discussion}

In the present study, light microscopic examination of Group III, in which rats received acrylamide for 20 days, showed histopathological changes as abnormal wavy course of the skeletal muscle fibers with splitting of the myofibers and fragmentation of the sarcoplasm. These findings are in agreement with the results of Cullen et al., (2001) [13] that explained the splitting of muscle fibers as an adaptive response, which occurs when the fiber reaches a critical size at which supply of oxygen and exchange of metabolites are no longer efficient.

In the current study, vascular congestion and fibrosis, in between the skeletal muscle fibers, and mononuclear cellular infiltration also appeared. These changes were also observed by Rasha and Fatma (2015) [8] and Oishi et al., (2006) [14] in their study of the toxic effects of acrylamide, they noticed that in association with increased oxidative damage of the skeletal muscle fibers vascular
Table (2): The mean PAS optical density in all groups using ANOVA test.

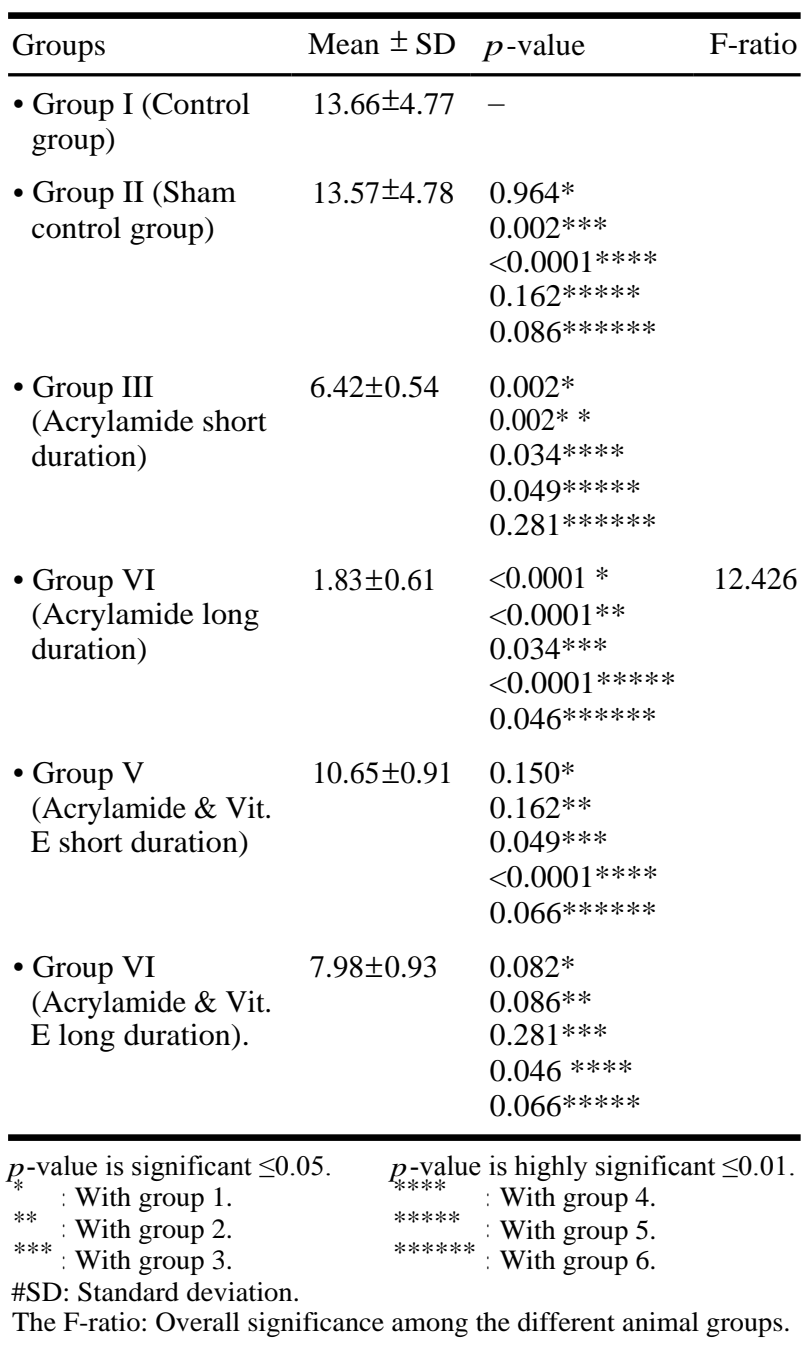

congestion, and perimuscular and perivascular fibrosis were detected that coincides with the results of our study. Also, Maronpot et al., (2015) [15] noticed in their study muscle fiber degeneration accompanied by inflammatory cell responses including mononuclear cellular infilteration and fibrosis.

Stevens and Lowe (2000) [16] explained that mononuclear cellular infiltration and fibrosis could be due to the release of certain mediators during degeneration of myocytes which initiate inflammatory reaction and attract inflammatory cells. This explanation was confirmed also by Nie and $\mathrm{Hou}$ (2012) and agreed with the findings of our study.

In our study, dense pyknotic nuclei and remnants of nuclei were observed. This agrees with the results of Prasad (2012) [9], which stated that exposure to acrylamide induces cytotoxic and genotoxic effects and promotes apoptosis. Weiss et al., (2013) [17] also noticed these changes and 
mentioned that they were associated with increased oxidative stress.

In Group IV, the previous histopathological changes were exaggerated with prolongation of the duration of exposure, as regard the fragmentation and splitting of the skeletal muscle fibers, in between the skeletal muscle fibers, the mononuclear cellular infiltration and vascular congestion, dilatation and fibrosis. This was confirmed previously by Shinomol et al., (2013) [13] and Rasha and Fatma (2015) [8], as they stated that the toxic effects of acrylamide is a dose dependent which increased by increasing the dose or the duration.

In our study, electron microscopic examination of skeletal muscle fibers of Group III showed degenerated parts of myofibrils, these results agrees with El-Sayyad et al., (2011) [5] and Shipp et al., (2006) [18], that reported that sections of the skeletal muscles of tongue of rats treated with acrylamide showed focal necrotic zones associated with lacking of their regular arrangement. Fusion of some mitochondria to form giant ones and vacuolation of others, disruption of $\mathrm{Z}$ line and partial loss of myofilaments were observed, these results agrees with the findings of Ghanayem et al., (2005) [19] and Lakshmi et al., (2012) [20]. Lakshmi et al., (2012) [20] stated that mitochondrial dysfunction has an important role in acrylamide induced toxicity.

By 40 days of exposure in Group IV, these changes were markedly exaggerated. These results and effect of acrylamide on mitochondria was described previously by El-Sayyad et al., (2011) [5] and Yang et al., (2005 [21]). It also stated that morphological mitochondrial abnormalities are most frequently associated with defects of the respiratory chain. Subsarcolemmal accumulations of mitochondria and their proliferation were also found and explained by Youssef (2006) [22] as an attempt by the cell to compensate for the respiratory chain defect.

The findings of the current study are mostly related to the oxidative stress effect of acrylamide on the skeletal muscle and it coincides with the study of Hori et al., (2013) [23] who stated that destruction of muscle fibers with oedema and inflammatory cell infiltration are prominent features of oxidative stress effect on skeletal muscle fibers. Their findings were also observed in our study as there were degenerated segments of the muscle fibers and mononuclear cellular infiltration in Group III and increased more in Group IV.
In our results, apoptosis which is presented by appearance of dense pyknotic nuclei and remnants of nuclei could be explained also by the oxidative stress damage effect of acrylamide on skeletal muscle which proved by Sumizawa et al., (2009) [24] and Lakshmi et al., (2012 [20]). They stated that oxidative stress and apoptosis play an important role in acrylamide induced toxicity.

In the current study, there are statistically significant increase in collagen fibers deposition and decrease in PAS optical density in Group III and IV than the control group and Group IV than Group III. These results coincide with Youssef (2006) [22], Catalgol et al., (2009) [25] and Huda et al., (2017) [26] who explained that these findings are indicators of oxidative stress in skeletal muscle fibers of acrylamide exposed rats that increased by prolongation of the duration of exposure.

In the present study, Vitamin $\mathrm{E}$ was administrated in combination with acrylamide for two different durations. The histological picture was improved in Group V (treated group for 20 days) and Group VI (treated group for 40 days) than the non-treated Groups (III and IV respectively). Histological sections of the skeletal muscle fibers of Vitamin E treated rats of Group V and VI revealed an apparently preserved architecture. This finding comes in accordance with Rasha and Fatma (2015) [8]. Also Nisreen et al., (2017 [27]) suggested that Vitamin E can eliminate free radical damage that induces apoptosis. Bermudz et al., (2007) [28] added that the antiapoptotic effects of Vitamin E are primarily associated with its antioxidant activity. Vitamin $\mathrm{E}$ has also been shown to induce protective effects and prevent apoptosis in many experimental model systems.

In the present study, Vitamin E treated Group $\mathrm{V}$ appeared with minimal amount of collagen fibers deposition in Masson trichrome stained sections and a positive reaction was observed in PAS stained sections, these coincides with Hoda et al., (2017), who stated that Vitamin E supplementation with acrylamide significantly protected and prevented oxidative stress induced degenerative changes and promotes regeneration.

In our study, the electron microscopic examination of the skeletal muscle fibers of Group V and Group VI showed nearly preserved normal structure. Most of cell organelles were intact. Mild focal degeneration occasionally found. These findings were confirmed by Rasha and Fatma (2015 $[8])$. 
In the present work, there are statistically significant decrease in collagen fibers deposition and increase in PAS optical density in Group V and VI than Group III than Group IV respectively. These findings are indicator of oxidative stress in skeletal muscle fibers of acrylamide exposed rats that decreased by Vitamin E co-administration. These results coincide with the findings of Shinomol et al., (2013) [13] and Rasha and Fatma (2015) [8]

From the present study, it could be concluded that, acrylamide induced skeletal muscle damage in rat tongue which increasing by prolonged duration of exposure. Acrylamide induced oxidative stress is the implicated mechanism of such histological changes. This toxic effect of acrylamide could be decreased by administration of Vitamin E given concomitant with it. This protective role of Vitamin E may be due to its antioxidant effect.

\section{References}

1- PARK H.R., KIM M.S., KIM S.J., PARK M., KONG K.H. and KIM H.S.: Acrylamide induces cell death in neural progenitor cells and impairs hippocampal neurogenesis. Toxicol. Lett., 193 (1): 86-93, 2010.

2- MANNAA F., ABDEL-WAHHAB M.A., AHMED H.H. and PARK M.H.: Protective role of Panax ginseng extract standardized with ginsenoside $\mathrm{Rg} 3$ against acrylamideinduced neurotoxicity in rats. J. Appl.Toxicol., 26 (3): 198-206, 2006.

3- KHAN M. A., DAVIS C.A., FOLEY G.L., FRIEDMAN M.A. and HANSEN L.G.: Changes in thyroid gland morphology after acute acrylamide exposure. Toxicol. Sci., 47: 151-7, 2016.

4- RODRÍGUEZ-RAMIRO I., RAMOS S., BRAVO L., GOYA L. and MARTÍN M.Á.: Procyanidin B2 and a cocoa polyphenolic extract inhibit acrylamide-induced apoptosis in human Caco- 2 cells by preventing oxidative stress and activation of JNK pathway. J. Nutr. Biochem., 22 (12): 1186-94, 2011.

5- EL-SAYYAD H., SOAD A.K., AFAF A.E., EMAN A. and EHSA M.A.: The effect of acrylamide or food supplementation of fried potato chips on the digestive tract of rats. J. Pharma. Reports, pp. 14-8, 2011.

6- FREDERICK A., BELA G.R., OLSON C.B., MENDOZA M., MATILDE M. and DANIEL R.D.: Carcinogenicity of glycidamide in $\mathrm{B} 6 \mathrm{C} 3 \mathrm{~F} 1$ mice and $\mathrm{F} 344$ rats from a two-year drinking water exposure. Food. Chem. Toxicol., 86: 104-15, 2015.

7- EL-SAYYAD H., SOAD A.K., AFAF A.E., EMAN A. and EHSAN M.A.: Abnormal soft palate, lingual mucosa and intestine of neonates maternally fed on diet containing fried potatoes chips or received acrylamide treatment. J. Pharma. Reports., pp. 12-20, 2017.

8- RASHA H. and FATMA M.: The impact of Vitamin E against acrylamide induced toxicity on skeletal muscles of adult male albino rat tongue: Light and electron microscopic study. J. Microsc. Ultrastruct., 3 (3): 137-47, 2015.
9- PRASAD S.N.: Evidence of acrylamide induced oxidative stress and neurotoxicity in Drosophila melanogaster and its amelioration with spice active enrichment: Relevance to neuropathy. Neurotoxicology, 33 (5): 1254-64, 2012.

10- RAHANGADALE S., JANGIR B.L., PATIL M., VERMA T., BHANDARKA A. and SONKUSALE P.: Evaluation of protective effect of Vitamin E on acrylamide induced testicular toxicity in wistar rats. ToxicolInt, 19 (2): 15861, 2012.

11- SHINOMOL G.G., RAGHUNATH N. and BHARATH M.M.: Prophylaxis with Bacopamonnieri attenuates acrylamide induced oxidative damage via elevated antioxidant function. Cent. Nerv. Syst. Agents .Med. Chem., 13: 312, 2013.

12- MEHRI S., KARAMI H.V., HASSANI F.V. and HOSSEINZADEH H.: Chrysin reduced acrylamide-induced neurotoxicity in both in vitro and in vivo assessments. Iran. Biomed. J., 18 (2): 101-6, 2014.

13- CULLEN M.J., JOHNSON M.A. and MASTAGLIA F.L.: Pathological reactions of skeletal muscle. In: Skeletal muscle pathology. Edinburgh: Churchill Livingstone, pp. 123-84, 2001

14- OISHI Y., YAMAMOTO H., NAGANO M., MIYAMOTO E. and FUTATSUKA M.: The effects of 2,5-hexanedione and acrylamide on myosin heavy chain isoforms of slow and fast skeletal muscles of the rat. Toxicol. Appl. Pharmacol., 139 (1): 15-21, 2006.

15- MARONPOT R.R., THOOLEN R.J. and HANSEN B.: Two-year carcinogenicity study of acrylamide in Wistar Han rats with in utero exposure. Exp. Toxicol. Pathol., 67: 189-95, 2015.

16- STEVENS A. and LOWE J.: Tissue response to damage. In: Pathology, ed., Mosby, New York, pp. 35-60, 2000.

17- WEIS D.J., CASAL G.P., KOUTAKIS P., NELLA A.A., SWANSON S.A. and ZHU Z.: Oxidative damage and myofiber degeneration in patients with peripheral arterial disease. J. Transl. Med., 25: 11-230, 2014.

18- SHIP A., LAWRANCE G., GENTRY R., MCDONALD T., BARTOW H. and BOUNDS J.: Acrylamide: Review of toxicity data and dose response analyses for cancer and non cancer effects. Crit. Rev. Toxicol., 36 (6-7): 481608, 2006.

19- GHANAYEM B.I., MCDANIEL L.P., CHURCHWEL M.I., TWADDLE N C., SNYDER R. and FENNELL T.R.: Role of CYP2E1 in the epoxidation of acrylamide to glycidamide and formation of DNA and hemoglobin adducts. Toxicol. Sci., 88 (2): 311-8, 2005.

20- LAKSHMI D., GOPINATH K., JAYANTHY G., ANJUM S., PRAKAS D. and SUDHANDIRAN G.: Ameliorating effect of fish oil on acrylamide induced oxidative stress and neuronal apoptosis in cerebral cortex. Neurochem Res., 37 (9): 1859-67, 2012.

21- YANG H.J., LEE S.H., JIM Y., CHOI J.H., HAN H.C. and LEE M.H.: Genotoxicity and toxicological effects of acrylamide on reproductive system in male rats. J. Vet. Sci., 2: 103-9, 2005.

22- YOUSSEF M.I.: Acrylamide induced oxidative stress and biochemical perturbations in rats. Toxicology, 219 (1-3): 133-41, 2006. 
23- HORI K., TSUJII M., IINO T., SATONAKA H., UEMURA T. and AKEDA K.: Protective effect of edaravone for tourniquet-induced ischemia-reperfusion injury on skeletal muscle in murine hindlimb. BMC. Musculoskelet. Disord., 27: 14-3, 2013.

24- SUMIZAWA T. and IGISU H.: Suppression of acrylamide toxicity by carboxyfullerene in humanneuroblastoma cells in vitro. Arch. Toxicol., 83 (9): 817-24, 2009.

25- CATALGOL B., OZHAN G. and ALPERTUNGA B.: Acrylamide induced oxidative stress in human erythrocytes. Hum. Exp. Toxicol., 28 (10): 611-7, 2009.
26- HODA A., GHALIA M.A., HASSAN M.R. and ELSHAFEY M.: Effect of Vitamin E on biochemical and ultrastructural changes in acrylamide induced renal toxicity in rats. Int. J. Sci. Rep., pp. 3 (5): 134-43, 2017.

27- NISREEN A.R. and NAJLAA M.: Antioxidant effect of Vitamin $\mathrm{E}$ and 5-aminosalicylic acid on acrylamide induced kidney injury in rats. Saudi. Med. J., 38 (2): 1327, 2017.

28- BERMUDZ Y., AHMADI S. and LOWELL N.E.: Vitamin EE suppresses telomerase activity in ovarian cancer cells. Cancer Detect. Prev., 31: 119-28, 2007. 3 (5): 134-43, 2017.

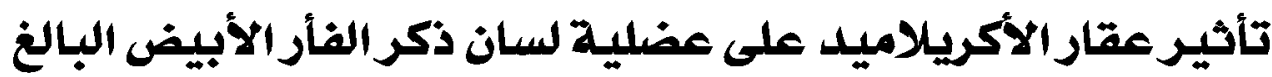

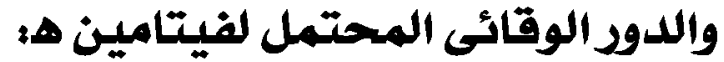 دراسة بالمجهرين الضوئى والإلكترونى لفئين}

المقدمة: تسبب مادة الاكريلاميد مشكة صحية وبيئية عامة، يتتج التعرض المباشر لمادة الاكريلاميد عن طريق تتاول الأطعمة بالكربوهيدرات التى يتم إعدادها في درجات حرارة عالية.

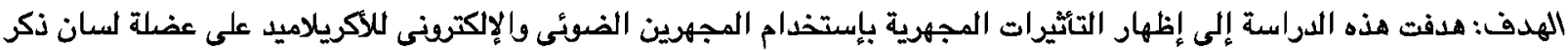

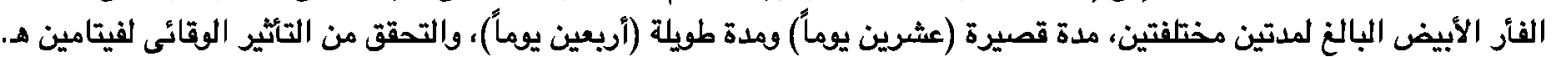

مواد وطرق البحت: تم تقسيم .7 من ذكود الجرذان البيضاء إلى ست مجموعات، تضم كل مجموعة عشرة فئران. المجموعة الأولى

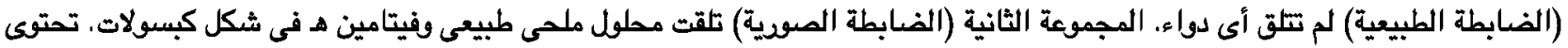

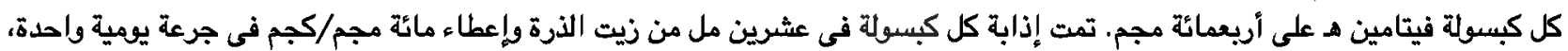

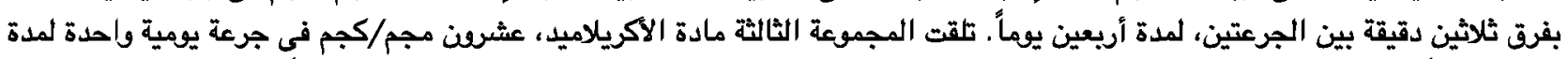

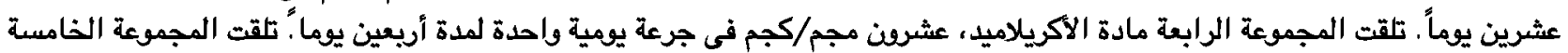

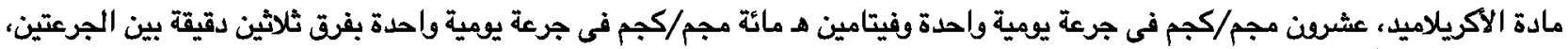

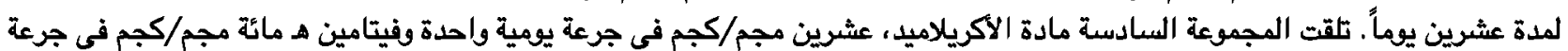

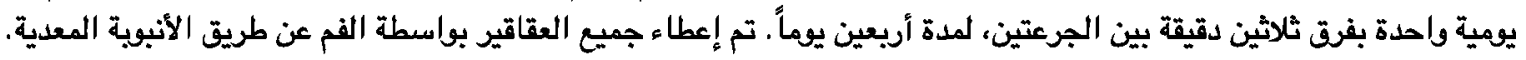

$$
\text { فى نهاية التجرية تم تشريح اللسان من أجل دراسة المجهرين الضوئى والإكترنى. }
$$

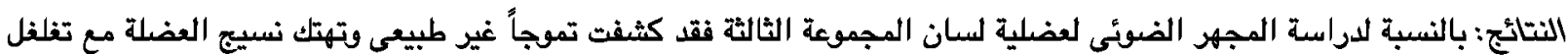

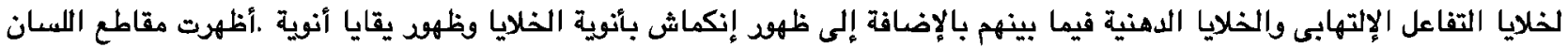

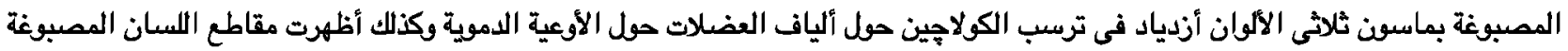

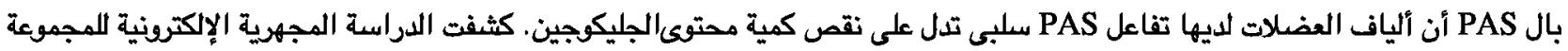

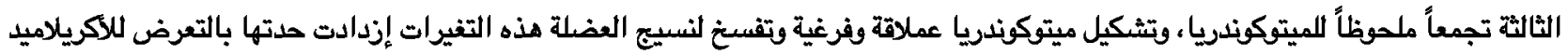

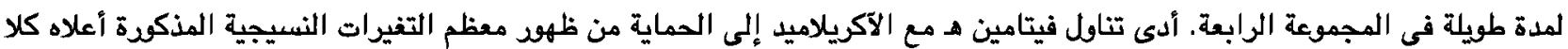
المجموعتين الخامسة والسادسة.

الخاتمة: يمكن الأستتتاج أن التعرض للاكريلاميد يؤدى إلى تلف عضلية لسان الجرذ والذى يصبح أسوأ مع طول فترة التعرض. يمكن

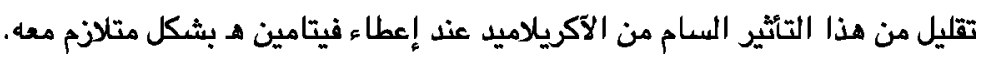

